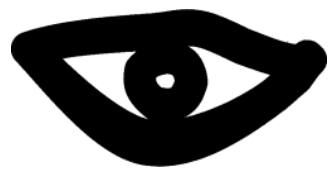

\title{
Conflito na legislação brasileira referente à escolarização de seus jovens atletas
}

\author{
Ricardo Antonio Torrado de Carvalho*, Celia Maria Haas** \\ *Mestre em Educação - Universidade Cidade de São Paulo - Brasil \\ **Professora titular do Programa de Mestrado em Educação - Universidade Cidade de São Paulo - Brasil
}

\begin{abstract}
Resumo
$\mathrm{O}$ artigo apresenta os resultados da pesquisa que tinha como objetivo investigar a legislação educacional e esportiva brasileira no que se refere à escolarização de seus jovens talentos esportivos. Com esse fim, realizou-se um levantamento bibliográfico dos materiais produzidos sobre escolarização de atletas e uma pesquisa das leis nacionais e estaduais, da educação e do esporte, que versam sobre o acesso e a permanência dos jovens talentos esportivos nas instituições escolares e universitárias. Como resultado, detectou-se flagrante contradição entre a legislação esportiva e a legislação educacional quanto ao controle de frequência dos alunosatletas na educação básica e superior.

Palavras-chave: escolarização de atletas, políticas educacionais, políticas no esporte.
\end{abstract}

\section{Abstract}

This article aimed to investigate the Brazilian educational and sports law regarding the education of their young sporting talents. To this end, we proceeded to a literature review of materials produced on school athletes and a survey of national and state laws, education and sport, which deal with access and permanence of young sporting talents in school enrollment and university. As a result, it detected a flagrant contradiction between the sports legislation and education legislation regarding the frequency control of the student-athletes.

Keywords: school athletes, educational policies, policies on sport.

\section{Introdução}

Os estudos sobre escolarização e formação de jovens atletas indicam que conciliar as obrigações escolares e as exigências esportivas torna-se uma grande dificuldade para os jovens talentos esportivos brasileiros.

Para Damo (2007, p. 43), "a carreira do esportista é muito específica se comparada às outras carreiras convencionais. Sua aposentadoria em média é muito precoce, com aproximadamente trinta e cinco anos. Desde o início da carreira, o jovem atleta participa de árduos treinamentos nos clubes, realiza repetições de movimentos e submete-se a trabalhos físicos extenuantes".

A rotina com treinamentos físicos e jogos, desde muito cedo, é também observado por Soares (2009) como um problema no processo de escolarização de atletas e por Correia (2014) que constatou já haver atletas federados, isto é, com compromissos de jogos e treinos, pelo menos a partir dos doze anos em todas as modalidades esportivas. Para Soares (2009, p. 17), "essa rotina nas categorias de base acarreta dificuldades no processo de escolarização típico dos jovens trabalhadores, entre elas, o cansaço físico e a falta de tempo para os estudos".

O desafio de conciliar a carreira esportiva e a escolar também é tratado nos estudos de Melo (2010) ao constatar que, os atletas, empenhados em consolidar a sua carreira, tendem a se descuidar dos estudos, e isso se agrava ainda mais se levarmos em consideração que a sua agenda como atleta entra muitas vezes em confronto com a sua rotina escolar. Todavia, segundo o autor, a relação com estudo parece ter um sentido diferente para o voleibol.

Correia (2014) constatou em sua pesquisa de mestrado que a necessidade de conciliação entre o esporte e a educação começa mais cedo entre os atletas do futebol e atletismo, se comparada aos atletas de voleibol, que apresentam uma taxa de repetência escolar baixa e os horários de competições e treinamento dificilmente conflitam com o horário escolar.

Em relação a atraso escolar de atletas, de acordo com Melo (2010), na modalidade de voleibol, o número de atletas que apresentam atraso na relação idade $\mathrm{x}$ série é baixo se compararmos também com o futebol, que apresenta atraso escolar de 46,89\%.

No futebol, Correia (2014, p. 4), afirma que, "desde os quatro anos os atletas têm de realizar esta empreitada de conciliar treinos, jogos e escola". O fato de o esporte ter-se tornado uma atividade econômica, não apenas de entretenimento e lazer, também altera o modo de a sociedade valorizar o segmento, no que concorda Epiphanio (2002, p. 16) ao afirmar que devido a essa valorização do esporte e mais especificamente do futebol no Brasil, "muitos jovens decidem ingressar desde a mais tenra idade nas mais variadas modalidades esportivas com o fim de praticar uma atividade física, mas principalmente de se profissionalizar e alcançar a posição de destaque de seus ídolos, evidenciando que no Brasil o esporte é muitas vezes encarado como uma promessa profissional".

Correia (2014), em sua dissertação e Bueno (2012), também em sua dissertação, veem esse avanço econômico no esporte como espetacularização do setor. Segundo os autores, a percepção da possibilidade de auferir capital econômico e social atrai, rapidamente, muitos jovens para o esporte na tentativa de profissionalização.

Segnini (2000, p. 24) afirma que "a escola está longe de ser o caminho de ascensão social para a 
maioria dos que completam o Ensino Fundamental". Complementando a afirmação, Soares $(2009$, p. 13), diz que "existe no Brasil uma série de fatores favoráveis que levam os jovens de baixa renda a apostarem na profissão de jogador de futebol: a precariedade da escola pública brasileira, o mercado de trabalho para as novas gerações, somada às poucas oportunidades de ascensão social".

Podemos destacar que a permanência do atleta na escola é altamente impactada pela busca constante de rendimento esportivo e, consequentemente, de ascensão profissional. É o que também aponta Balzano (2012) em relação à permanência de jovens talentos esportivos na escola.

A permanência na escola dos jovens atletas futebolistas vem diminuindo cada vez mais no decorrer dos anos. De acordo com Balzano (2012, p. 7) muitos meninos sonham em ter um futuro brilhante no futebol, e com o mesmo uma ascensão financeira. Contudo, após ingressarem em uma equipe de futebol, visando uma oportunidade de crescimento, muitas vezes acabam abandonando os estudos, e não chegam a concluir o ensino médio.

A concorrência do tempo esportivo e do escolar é muito comum no processo de formação de algumas modalidades esportivas no Brasil. Segundo Damo (2005, p.23), 'a busca pela profissionalização pode começar antes mesmo dos 12 anos de idade e implica aproximadamente cinco mil horas de prática de atividades corporais específicas ao longo de 10 anos'.

Soares (2011) pondera que a dedicação aos estudos até permite maior possibilidade de ocupação na vida adulta, mas sua recompensa está longe do imediatismo de muitos jovens.

Os estudos sobre escolarização dos atletas apresentam as dificuldades que estes encontram em conciliar as obrigações esportivas e escolares, sugerindo que clubes e escolas estejam mais próximos, flexibilizando e harmonizando as duas atividades, permitindo que seus jovens talentos esportivos permaneçam nos estudos, além de valorizá-los diante do aspecto financeiro percebido por meio do futebol.

Além dessas dificuldades, outro problema acaba, por consequência, surgindo: A frequência escolar desses alunos atletas. Portanto, há de se explorar os limites legais impostos pela legislação esportiva e educação brasileira aos clubes e instituições de educação superior no controle de presença destes alunos.

\section{Metodologia}

Sobre o processo de escolarização de atletas realizou-se um levantamento no banco de teses da Capes, no período de 2010 a 2014, com o descritor "escolarização de atletas". Por meio desse recurso, identificaram-se três dissertações de mestrado, Barreto (2012), Santos (2011) e Medeiros (2012), e uma tese de doutorado, de Costa (2012). Destes, foram listados os estudos de Barreto (2012) e Costa (2012), que analisaram a escolarização de atletas e fundamentaram o entendimento das dificuldades que o atleta encontra em conciliar obrigações esportivas e escolares ao longo de sua vida escolar. No contexto de escolarização de atleta, encontra-se também disponível na biblioteca eletrônica Scielo, a dissertação de mestrado de Correia (2014) que tratou da formação esportiva e escolar dos jovens atletas da Escola Vasco da Gama, que pertence ao Clube de Regatas Vasco da Gama - RJ.

No que se refere à legislação esportiva, foram consultadas leis que versam sobre a responsabilidade dos clubes na escolarização dos atletas: a lei 13.748 , de 8 de outubro de 2009, que determina aos clubes de futebol que assegurem matrícula em instituição de ensino aos jogadores menores de 18(dezoito) anos a eles vinculados; a Lei 9.615, de 24 de março de 1998, que institui normas gerais sobre desporto; a lei 10.891, de 9 de julho de 2004, que institui a Bolsa-Atleta e cria os Programas Atleta Pódio e Cidade Esportiva; revoga a lei 6.354, de 2 de setembro de 1976, e dá outras providências e a lei 12.395 , de 16 de março de 2011. Quanto à legislação educacional, foi consultadas a Lei de Diretrizes e Bases da Educação Nacional (LDB) que versa sobre a frequência escolar, abonos de faltas e exercícios domiciliares na educação básica e superior.

\section{A legislação esportiva}

Diante das dificuldades observadas em relação a conciliação entre as obrigações esportivas e escolares, convém examinar o que a legislação esportiva brasileira diz sobre a escolarização dos atletas.

Dentre as leis esportivas, se destaca a Lei 9.615, de 1998, conhecida como a Lei Pelé, que institui normas gerais sobre o desporto brasileiro e dá outras providências. No contexto esportivo-educacional, observou-se que a citada lei trata da ausência escolar em detrimento a atividades esportivas somente a "atleta servidor público civil ou militar, da Administração Pública direta, indireta, autárquica ou fundacional, convocado para integrar representação nacional em treinamento ou competição desportiva no País ou no exterior", conforme dispõe o art. 84, transcrito em seguida:

Art. 84. Será considerado como efetivo exercício, para todos os efeitos legais, o período em que o atleta servidor público civil ou militar, da Administração Pública direta, indireta, autárquica ou fundacional, estiver convocado para integrar representação nacional em treinamento ou competição desportiva no País ou no exterior. (Redação dada pela Lei $\mathrm{n}^{\circ}$ 9.981, de 2000).

$\S 1^{\circ} \mathrm{O}$ período de convocação será definido pela entidade nacional da administração da respectiva modalidade desportiva, cabendo a esta ou aos Comitês Olímpico ou Paraolímpico Brasileiros fazer a devida comunicação e solicitar ao INDESP - Instituto Nacional de Desenvolvimento do Desporto - a competente liberação do afastamento do atleta ou dirigente. (Redação dada pela Lei $n^{\circ}$ 9.981, de 2000).

$\S 2^{\circ} \mathrm{O}$ disposto neste artigo aplica-se, também, aos profissionais especializados e dirigentes, quando indispensáveis à composição da delegação. 
Não há, portanto no art. 84 a previsão de abono de faltas ou exercícios domiciliares para o estudanteatleta. Entretanto, o art. 29 da referida lei atribui às instituições esportivas formadoras a responsabilidade de garantir a matrícula do jovem na escola, ajustar o tempo de treinamento aos horários do currículo escolar e exigir sua frequência e aproveitamento satisfatório. No art. 85, indica-se ainda que os sistemas de ensino, em suas diferentes esferas, definirão normas específicas para verificação do rendimento e o controle de frequência dos estudantes que integrarem representação desportiva nacional, de forma a harmonizar a atividade desportiva com os interesses relacionados ao aproveitamento e à promoção escolar (BRASIL, 1998).

Já no âmbito estadual, a Lei 13.748 , de 8 de outubro de 2009, atribui, aos clubes de futebol oficiais do Estado de São Paulo a responsabilidade pela escolarização de seus atletas, conforme dispõe o art. 1, transcrito em seguida:

Artigo $1^{\circ}$ - Os clubes de futebol oficiais do Estado devem assegurar que estejam matriculados em instituição de ensino, pública ou particular, todos os jogadores menores de 18 (dezoito) anos com os quais possuam qualquer forma de vínculo, zelando pela sua frequência e aproveitamento escolar. Parágrafo único - Consideram-se clubes oficiais as associações devidamente registradas e reconhecidas pela Federação Paulista de Futebol.

Artigo $2^{\circ}$ - $\mathrm{O}$ descumprimento da obrigação do artigo anterior acarretará a aplicação das penalidades de multa e de impedimento de participação em torneios e competições oficiais.

$$
\text { (...) }
$$

$\S 2^{\circ}$ - A não entrega dos comprovantes de matrícula e frequência escolar dos jogadores menores de 18 (dezoito) anos, pelos clubes oficiais, à Federação Paulista de Futebol presumirá o descumprimento desta lei, acarretando a aplicação das penalidades.

Parece claro pelas leis citadas que os clubes são responsáveis por assegurar a matrícula escolar de seus atletas, bem como por zelar pela sua frequência e rendimento satisfatório dos mesmos. Em nível superior, sugere-se que as Instituições de Educação Superior venham a criar regras e normas aos seus atletas bolsistas quanto ao rendimento e frequência dos mesmos nas atividades acadêmicas. Assim, a Instituição poderá traçar ações para que seu atleta bolsista concilie as atividades esportivas e acadêmicas. Entretanto, vale ressaltar que, perante as normas pré-estabelecidas pela legislação educacional as Instituições de Ensino não poderiam de forma alguma justificar ausência escolar por motivos esportivos, tampouco prescrever atividades domiciliares aos alunos atletas.

\section{A legislação educacional}

De acordo com o parecer CNE/CES 224/2006, do Conselho Nacional, aprovado em 20/9/2006, o art. $47, \S 3^{\circ}$, da Lei das Diretrizes e Bases da Educação Nacional (LDB) 9.394, de 20 de dezembro de 1996, é obrigatória a frequência de alunos e professores, salvo nos programas de educação a distância, que se regem por outras disposições. Não existe legalmente abono de faltas na educação básica.

É admitida, para a aprovação, a frequência mínima de $75 \%$ do total às aulas e demais atividades escolares, em conformidade com o disposto na Resolução 4, de 16/9/86, do extinto Conselho Federal de Educação. Cabe destacar que a LDB, art. 24, inciso VI, assinala dois pontos importantes que compete aos sistemas de ensino observar. Primeiro, que o controle de frequência deve ficar a cargo da escola e estar consignado no seu regimento escolar, bem como no do respectivo sistema de ensino. Em segundo lugar, estabelece que a frequência mínima exigida para a aprovação dos estudantes é de setenta e cinco por cento do total de horas letivas. O Parecer CNE/CEB 5/97, determinam que o controle da frequência contabilize a presença do aluno nas atividades escolares programadas, das quais está obrigado a participar em pelo menos $75 \%$ do total da carga horária prevista. Desse modo, a insuficiência revelada na aprendizagem pode ser objeto de correção, pelos processos de recuperação a serem previstos no regimento escolar. As faltas, não. A lei fixa a exigência de um mínimo de $75 \%$ (setenta e cinco por cento) de frequência, considerando o "total de horas letivas para aprovação". O aluno tem direito a faltar até o limite de $25 \%$ (vinte e cinco por cento) do referido total. Se ultrapassar este limite estará reprovado no período letivo correspondente. A frequência de que trata a lei é apurada sobre o total da carga horária do período letivo. Não há tampouco na educação superior abono de faltas, exceto nos seguintes casos, segundo o Decreto-Lei 715/69 (BRASIL, 1998):

- alunos reservistas: o Decreto-Lei n ${ }^{\circ} 715 / 69$ assegura o abono de faltas para todo convocado matriculado em órgão de formação de reserva ou reservista que seja obrigado a faltar às atividades civis por força de exercício ou manobra, exercício de apresentação das reservas ou cerimônias cívicas, e o Decreto $n^{\circ} 85.587 / 80$ estende essa justificativa para o oficial ou aspirante-a-oficial da reserva, convocado para o serviço ativo, desde que apresente o devido comprovante (a lei não ampara o militar de carreira; portanto suas faltas, mesmo que independentes de sua vontade, não terão direito a abono);

- aluno com representação na CONAES: de acordo com a lei que instituiu o Sistema Nacional de Avaliação da Educação Superior (SINAES), as instituições de educação superior devem abonar as faltas do estudante que tenha participado de reuniões da CONAES em horário coincidente com as atividades acadêmicas.

As situações em que a falta às aulas pode ser preenchida por exercícios domiciliares são regulamentadas pelo Decreto-Lei 1.044, de 21 de outubro de 1969. Nos casos citados, o interessado deve protocolar requerimento junto à instituição, apresentando os documentos comprobatórios (laudo médico com indicação do período previsto e outros) para avaliação da instituição. A sua aplicação deverá ser considerada institucionalmente, caso a caso, de modo 
que qualquer distorção, por parte do aluno ou da instituição de ensino, possa ser corrigida com a adoção de medidas judiciais pertinentes. Estudantes grávidas são amparadas pela Lei 6.202/1975, cujo art. $1^{\circ}$, dispõe que, a partir do oitavo mês de gestação, e durante três meses, a estudante grávida ficará assistida pelo regime de exercícios domiciliares.

\section{Conclusão}

No que se refere ao aspecto legislativo, detectou-se flagrante contradição entre a legislação que disciplina os critérios de aprovação na educação superior, no que se refere à exigência da presença dos alunos em sala de aula e da legislação esportiva que orienta a conciliação entre as competições esportivas e o calendário escolar.

Observou-se que não há na legislação educacional determinação alguma que abone, ou possibilite o abono das ausências dos atletas em suas atividades escolares devido a compromissos esportivos, tampouco há a previsão de exercícios domiciliares pelos mesmos motivos.

Assim, poder-se afirmar sobre o amparo legal no que se refere a conciliar obrigações esportivas e estudantis que há evidencias claras de uma dissonância entre as legislações que disciplinam o abono ausências de alunos atletas, tampouco prescrever atividades assistidas aos mesmos e as proposições políticas que incentivam a inclusão dos atletas na Educação Superior. Tal fato leva, muitas vezes, ao apoio informal, ilegal e irregular da Instituição de Educação Superior para com seus alunos atletas, concretizada no acolhimento dos professores das dificuldades que os atletas enfrentam no que se refere a presença nas aulas. Destaca-se, portanto, um conflito legislacional ao tratar das condições dos atletas frequentarem suas atividades escolares, dificultando a resolução do problema por parte das Instituições Educacionais.

\section{Referencias}

BARRETO, P. H. G. Flexibilização escolar para atletas em formação alojados em centros de treinamento no futebol: um estudo na toca da raposa e na cidade do galo. 2012. 106 p. Dissertação (Mestrado em Educação Física) Programa de Pós-Graduação em Educação Física, Universidade Federal do Espírito Santo, Vitória, 2012.

BRASIL Lei 10.891, de 09 de julho de 2004. Institui o Bolsa-Atleta. Legislação Federal. sítio eletrônico internet - planalto.gov.br

BRASIL Lei 12.395, de 16 de março de 2011. Altera as Leis 9.615, de 24 de março de 1998, que institui normas gerais sobre desporto, e 10.891, de 9 de julho de 2004, que institui a BolsaAtleta; cria os Programas Atleta Pódio e Cidade Esportiva; revoga a Lei 6.354, de 2 de setembro de 1976 e dá outras providências. Legislação Federal. sítio eletrônico internet planalto.gov.br

BRASIL Lei $n^{\circ}$ 9.615, de 24 de março de 1998. Institui normas gerais sobre desporto e dá outras providências. Legislação Federal. sítio eletrônico internet - planalto.gov.br

BRASIL. Ministério da Educação e do Desporto. Lei $n^{\circ}$ 9.394 de 20 de dezembro de 1996: estabelece as diretrizes e bases da educação nacional. Brasília, 1996. Disponível em: http://portal.mec.gov.br/arquivos/pdf/ldb.pdf. Acesso em: 10 julho. 2013.

BUENO, L. Políticas Públicas do esporte no Brasil: razões para o predomínio do alto rendimento. 2008. 296 f. Tese (Doutorado em Administração Pública e Governo) - Escola de Administração de Empresas de São Paulo, Fundação Getúlio Vargas, São Paulo, 2008.

CALONIO, Cesar. A LEI 12.395 E A FORMAÇÃO DE ATLETAS NO BRASIL. XI Congresso Luso Afro Brasileiro de Ciências Sociais. Disponível em:

http://www.xiconlab.eventos.dype.com.br/reso urces/anais/3/1307102757_ARQUIVO_Artigo

_Calonio_Luna_Conlab.pdf $>$ Acessado em 10 $\overline{\text { de }}$ abril de $201 \overline{5}$.

CÂMARA DOS DEPUTADOS. Congresso Nacional. O que é Legislação? In http://www2.camara.gov.br/comissoes/cpcms/n ormativas/oqueelegislacao.html. 2007. Acesso em 09/01/2007.

CORREIA, Carlus Augusto Jourand. Entre a profissionalização e a escolarização: projetos e campo de possibilidades em jovens atletas do Colégio Vasco da Gama. Rio de Janeiro, 2014. 240 f. Dissertação (Mestrado em Educação) Programa de Pós-graduação da Faculdade de Educação no Centro de Filosofia e Ciências Humanas da Universidade Federal do Rio de Janeiro, 2014.

COSTA, Felipe Rodrigues. A escola, o esporte $e$ a concorrência entre estes mercados para jovens atletas mulheres no futsal de Santa Catarina. 2012. Tese (Doutorado em Educação Física) - Programa de PósGraduação em Educação Física, Universidade Federal do Rio de Janeiro, Rio de Janeiro, 2012.

DAMO, Arlei Sander. Do Dom à Profissão: formação de futebolistas no Brasil e na França. São Paulo: Aderaldo e Rothschild Editora, Anpocs, 2007.

EPIPHANIO, E. H. Conflitos vivenciados por atletas quanto à manutenção da prática esportiva de alto rendimento. Estudos em psicologia, 19, 15-22, 2002.

MARQUES, M. P. e SAMULSKI, D. M. Análise da carreira esportiva de jovens atletas de futebol na transição da fase amadora para a fase profissional: escolaridade, iniciação, contexto 
sócio-familiar e planejamento da carreira. Revista Brasileira de Educação Física e Esporte, São Paulo, v.23, n.2, p.103-19, abr./ jun. 2009.

MELO, L. B. S. Formação e escolarização de jogadores de futebol no Estado do Rio de Janeiro. 2010. 72 f. Dissertação (Mestrado em Educação Física)-Universidade Gama Filho, Rio de Janeiro, 2010.

RODRIGUES, F. X. F. A formação do jogador de futebol no Sport Club Internacional (19972002). Porto Alegre. Dissertação (Mestrado em Sociologia) - PPGS/UFRGS, 2003.

ROMÃO, M; COSTA, F.R; SOARES, A.J.G. Escolarização de equipes do voleibol no Rio de Janeiro. In.: XI CONGRESSO ESPÍRITOSANTENSE DE EDUCAÇÃO FÍSICA NAS POLÍTICAS PÚBLICAS: TRABALHO E GESTÃO INTEGRADA, 11., 2011, Vitória.

SANTOS, J. R. (1981). História Política do Futebol Brasileiro. São Paulo: Brasiliense.
SANTOS, T. C. (18 de junho de 2002). Globalização, mundialização e esporte: o futebol como megaevento. Acesso em 17 de março de 2014, disponível em Galiza CIG: http://www.galizacig.com/index.html

SÃO PAULO (Estado). Lei $n^{\circ}$. 13.748, de 8 de outubro de 2009. Determina aos clubes de futebol que assegurem matrícula em instituição de ensino aos jogadores menores de 18(dezoito) anos a eles vinculados. Diário Oficial do Estado de São Paulo, São Paulo, 18 nov. 2009. p.1.

SOARES, G. J. A.; MELO, de S. B. L.; BARTHOLO, L. T.; BARROS, P. de L. F.; BRANDI NETO, R. J. Mercado, escola e a formação dos jogadores de futebol no Brasil. Anais dos XVI Congresso Brasileiro de Ciências do Esporte e III Congresso Internacional de Ciências do Esporte Salvador - Bahia - Brasil 20 a 25 de setembro de 2009 